\title{
Diesel Engines and Coastal Shipping
}

D URING the meeting of the British Association at Norwich, an evening discourse was delivered on September 6 by Dr. S. J. Davies on Diesel engines and coastal shipping.

After referring to the remarks of Sir Frederick Bramwell in 1881 and the comments made by Sir Alfred Ewing in 1931 on Bramwell's suggestion that by 1931 steam engines would be superseded by internal combustion engines, Dr. Davies said that, for transport by road and in the air, the internal combustion engine holds a practical monopoly, but in large power stations the steam installation successfully meets competition. But the contest goes on, improvements in competing types appearing almost daily, while apparently unimportant developments in physics or metallurgy may have far-reaching consequences. The production of a better heat-resisting metal, for example, might change the whole position of the contest. The competition in the marine-engine field has proved one of the most interesting. On passenger liners the contest between the two divisions of steam engines, reciprocating and turbine, had first to be settled. To-day, while the steam turbine shows outstanding advantages for the largest passenger liners, Diesel engines have met with some success on the smaller liners, although the question is still very open. It is in the remaining classes of oceangoing vessels of the mercantile marine that Diesel engines have their greatest application, while in the last few years their importance in coastal work has steadily increased.

The term 'coastal shipping' includes a variety of craft, but for his purpose Dr. Davies confined himself to the three divisions : tugs, fishing vessels and coasters. In comparison with ocean-going vessels, these are limited in size and in the lengths of their voyages. These limitations involved factors quite different from those governing the design of ocean-going ships and their machinery. Ocean-going vessels spend by far the greater proportion of their time under way in travelling steadily at normal engine speeds, the proportion of time at reduced speeds and while manouvring in harbour being small. In other words, the loads on the engines are for the most part uniform, and the demands made in respect of repairs and overhauls consequently less exacting than in coastal vessels. An ocean-going ship might go for days without the engineers receiving any orders from the bridge, and all running conditions-such as cooling water temperature, injection, adjustments, etc.--can be set and left unchanged.
The coasting vessel, on the other hand, is steaming to bell most of the time ; entering ports and rivers, docking, turning and then steaming on to its next destination through relatively crowded waterways. It is thus essential that the engines of the coaster should continue to work without detail supervision, and that they should withstand without difficulty both the mechanical stresses imposed by rapid changes of load and speed, and also the changes of engine temperature involved. In coasting vessels, the opportunities for carrying out repairs and adjustments are more limited. Then, too, limitation of size involves other conditions. Whereas the ten-thousand ton vessel has a little spray blown over the engineroom hatchway in bad weather, a moderate breeze will cause a small coaster to be drenched with spray, and so the engine must be made waterproof. The coaster too, lying alongside quays, is exposed to dust and grit, and the machinery should be totally enclosed to avoid the wear of working parts from the abrasive action of the grit. It is therefore clear that the machinery works under most exacting conditions, and it is necessary that everything possible should be done to lighten the duties of the engineer and to facilitate the repair or renewal of engine parts.

The Diesel engine for coasters is still in the experimental stage. Many firms are entering the field, and the Diesel engine is justifying itself handsomely in certain applications. Nevertheless, the full benefits of the Diesel engine cannot be realised until a limited number of designs can be standardised. As a result of such standardisation, the first costs of the engines should be lower than at present, spare parts should be readily and cheaply supplied, and the proportion of time the vessel is laid up for overhauls should be reduced. One direction in which the duties of the engineer could be lightened is by removing the navigational control of the machinery from the engine-room to the bridge. The handle of what is normally the engine-room telegraph should be the control handle on the bridge, and the change of speed and reversing the propeller should be fully automatic in response to the movement of this handle.

Investigations into the wear of Diesel engine cylinder liners have demonstrated the bad effect of changes of temperature of the circulating water and in particular of running an engine with cold circulating water. Coastal vessels, with their rapid changes of load and speed, and relatively frequent stops, are especially subject to 
these unfavourable conditions, and it would be sound economy on all but the smallest vessels to take steps to reduce their effects. To ensure efficient cooling of the cylinders, cooling, in all but the smallest vessels, should be by fresh water passing round a closed circuit consisting of a small tank well above the engine, feeding into the line near the pump suction, and a tubular cooler placed well down in the ship. Clean lubricating oil is always an economy. This is provided by employing the 'dry sump system' in which the oil from the crank chamber is forced into a storage tank through filters which extract the solid particles. The filtered oil is drawn from the storage tank, and delivered under pressure to the engines.

While matters of design, control and upkeep are common to all classes of vessels, each kind of service brings its own special problems, and the examples quoted should show how these have been solved. Diesel engines for tugs have become of considerable importance in the last seven years. On the Thames, goods are carried in flat-bottomed barges which are towed downwards and upwards with the tide, the current at full ebb and flow being about 3 knots. There are approximately 350 tugs engaged in lighterage on the river, of which already 150 are motor tugs. The Thames Steam Tug and Lighterage Co. has been one of the pioneers in the use of Diesel engines, and one of their vessels has been in use for more than five years. In the Irande, the propelling machinery consists of a six-cylinder directly-reversible fourstroke Carels-Ingersoll-Rand engine developing 340 b.h.p. Another vessel of the same company, the Framfield, has two six-cylinder four-stroke engines, each driving a dynamo delivering current at 350 volts to a 400 s.h.p. propulsion motor. Control is from the bridge, there being two control handles, one on the port side and the other on the starboard side, so that the steersman can use the one most convenient to him. Mr. F. T. Mayor, the superintending engineer of the company, kindly supplied figures which made a comparison of the working costs of a steam tug and motor tug possible. These figures are very favourable to the motor tug.

As regard fishing vessels, the application of Diesel engines has been very uneven at the various ports. The Cornish fishermen, for example, have applied small engines to practically all their sailing vessels. The Scottish fishermen have gone further and have applied Diesel engines to many vessels of the sizes formerly steam-driven. The larger classes of trawlers, having displacements up to 2,300 tons, have engines of 1,000 h.p. and more. Several such vessels have been built in Great Britain, but mainly for French owners, and are employed in cod-fishing. There is a difference of opinion as to the question of drive in certain classes of fishing vessels. For the largest vessels, directly-reversing engines with direct drive to the propeller are usual ; for small vessels, combined speed-reduction and reversing gears give the best service. In view of the large mass of experience already gained at home and abroad with Dieselengined vessels, reliability in service may now be taken for granted. Other factors must, of course, be taken into account in making a comparison between steam engines and Diesel engines, and since the first costs of the latter are higher than those of the former, Diesel engines must show other advantages to counterbalance their higher capital charges. These compensating advantages follow mainly from two important facts : first, for the same power and output Diesel engines occupy considerably less space than the corresponding steam engines and boilers; secondly, the Diesel engine has a much higher thermal efficiency than the steam engine.

Turning to the third division of coastal vessels, the coasters, Dr. Davies said the primary duty of these is to convey goods, although small numbers of passengers are carried in some of the larger vessels. Among the companies who have recently adopted Diesel engines for coastal work is Messrs. Coast Lines, Ltd. The first of their four motorships was launched just two years ago and the fourth in July last. Their M.V. Pacific Coast has a dead-weight capacity of 1,755 tons. She is a twin-screw vessel, having two five-cylinder PolarDiesel two-stroke engines, each developing 628 b.h.p. at 250 r.p.m. The auxiliaries are all electrically driven, current being generated by three oil-driven dynamos.

Such large vessels, however, are exceptional and, in view of the smaller difference between their work and that of ocean-going vessels, the superiority of Diesel engines in their case could be almost taken for granted. In tugs and fishing vessels, too, the matter seems also to be clearly proved. It may be summarised broadly by saying that where the vessel is for the greater part of its time under way, the advantages of the Diesel engine more than balance its higher first cost.

Whether as a result of the application of the Diesel engine or not, there is an undoubted revival of interest in coastal shipping. That this question is being approached more scientifically than hitherto is to be seen in the recent report of the work of the Froude Tank at the National Physical Laboratory. It is interesting to note, too, that the researches carried out have led to results definitely favourable to engines driving propellers at higher speeds of revolution, which is usually the case when Diesel engines are employed. Dr. Davies' lecture throughout was illustrated with slides of the various types of craft and their machinery. 